В стихотворении «Гамаюн, птица вещая» Гамаюн также пророчески поет об апокалипсическом будущем: «На гладях бесконечных вод, / Закатом в пурпур облеченных, / Она вещает и поет, / Не в силах крыл поднять смятенных...» [3, с. 276]. С.А. Васильев обращает внимание на слова стихотворения «уста, запекшиеся кровью», символически указывающие на «страдание существа, несущего правду» [4, с. 8].

Примечательно изменение названия мифической птицы с «райской», что соответствует традиции жанра легенды, на «вещую». По преданиям мифическим Сирину, Алконосту, Гамаюну свойственно, подобно античным сиренам, очаровывающее пение, которое зовет в рай, а блоковская птица Гамаюн вещает «правду», сама страдая от нее.

Безусловно, орнитологическая символика в поэтическом мире А.А. Блока не ограничивается указанным перечнем птиц. Как правило, мифологемы птиц связаны с онтологическими категориями жизни и смерти, выполняя функцию связующего начала между двумя мирами. Орнитологическая символика в стихотворениях «Сирин и Алконост» и «Гамаюн, птица вещая» свидетельствует о глубине философских размышлений автора. Смысловое пространство символики птиц в блоковской лирике постигается через знакомство с авторской концепцией мифических птиц-дев Сирина, Алконоста, Гамаюна. Поэт, сохраняя в образах-мифологемах очаровывающее пение, меняет семантику, наделяя их новыми чертами: птицы выступают носителями «вещей правды», пророчествуют о будущем России, тем самым выражая авторское кризисное мировосприятие.

\section{Список литературь}

1. Авдеева Т.В. Райская птица в традиционной культуре восточных славян // Грамота. - 2013. - № 7(33). - Ч. 1. - С. 13-15.

2. Бень Е.Б. Гамаюн, Сирин и Алконост (Фольклор и живопись в двух стихотворениях А.Блока) // Русская речь. - 1985. - № 4. - С. 131136.

3. Блок А.А. Собрание сочинений: в 6 т. Т. 1. - М.: Художественная литература, 1980. - 552 с.

4. Васильев С.А. «Весны неведомой прилив...» (картины В.М. Васнецова и стихотворения А.А Блока) // Русская словесность. 2008. - № 3. - С. 7-11.

5. Мифы народов мира: Энциклопедия: в 2 т. / Гл.ред. С.А. Токарев. - М.: Большая Российская Энциклопедия, 2003. - $671 \mathrm{c.}$

6. Руднев И.С. Словарь культуры ХХ века: Ключевые понятия и тексты. - М.: Аграф, 1997. $381 \mathrm{c}$.

7. Хань У. Художественная семантика орнитологической образности русской и китайской поэзии первой трети XX в.: образ ласточки // Известия ВГПУ. Актуальные проблемы литературоведения. - 2014. - № 2(87). - С. 153-156.

\title{
THE REFERENCE WORD AND ITS ROLE IN THE FORMATION OF THE ANALYTICAL UNIT (BASED ON FRENCH, RUSSIAN AND OSSETIAN LANGUAGES)
}

\author{
Tsagolova Tatyana Tambievna \\ Mountain State Agrarian University, \\ Vladikavkaz, Republic of North Ossetia - Alania, Russia \\ DOI: $10.31618 /$ nas.2413-5291.2020.3.53.171 \\ ОПОРНОЕ СЛОВО И ЕГО РОЛЬ В ФОРМИРОВАНИИ АНАЛИТИЧЕСКОЙ ЕДИНИЦЫ \\ (НА МАТЕРИАЛЕ ФРАНЦУЗСКОГО, РУССКОГО И ОСЕТИНСКОГО ЯЗЫКОВ)
}

\author{
Цаголова Татьяна Тамбиевна \\ Горский Государственный Аграрный Университет, \\ 2. Владикавказ, Республика Северная Осетия-Алания, Россия
}

\begin{abstract}
Abstarct
One of the most important questions in the study of analytical structures is the definition of its supporting element, which plays a semantic role in the process of transformation of a free combination of words into an analytical unit. The definition of a support word as a "connecting" force is directly correlated with the structural type of the analytical model. In some cases, it will be identified with the grammatical core of the phrase. In other structural types, the core word will coincide with the grammatically subordinate component of the phrase. Other situations may arise.
\end{abstract}

\section{Аннотация}

Один из важнейших вопросов в изучении аналитических структур - это определение его опорного элемента, выполняющего смыслообразующую роль в процессе перерождения свободного сочетания слов в аналитическую единицу. Определение опорного слова как «связующей» силы непосредственно соотнесено со структурным типом аналитической модели. В некоторых случаях оно будет идентифицироваться с грамматическим стержнем словосочетания. В других структурных типах стержневое слово будет совпадать с грамматически подчинённой составляющей словосочетания. Могут складываться и иные ситуации.

Keywords: analytical structure; analytical model; collocation; reference word; color designations; Russian language; French. 
Ключевые слова: аналитическая структура; аналитическая модель; словосочетание; опорное слово; цветообозначения; русский язык; французский язык, осетинский язык.

Исследование проводилось в синхронносопоставительном плане на материале аналитических словосочетаний французского, русского и осетинского языков, отмеченных существенными различиями как собственно языковой, так и культурно-исторической природы.

Цель исследования заключалась в выявлении характера лексико-синтаксических процессов, структурирующих два вида словосочетаний: элементарные аналитические единицы и аналитические единицы фразеологической природы. Ключевым элементом выступают прилагательные цветовой триады: белое, чёрное, красное в трёх языках. Материалом исследования послужили наиболее авторитетные словари и литературные примеры из произведений французских, русских и осетинских авторов. Конкретная методика, применяемая в анализе языкового материала - комплексная, сочетающая в себе элементы описательно-сопоставительного и контрастивного методов.

Определение опорного слова как «связующей» силы непосредственно соотнесено со структурным типом аналитической модели.

Чтобы лучше разобраться в процессах выдвижения слов на роль опорного элемента словосочетания, обратимся к выявлению некоторых особенностей сочетаемости слов.

Стало уже общеизвестным тонкое наблюдение А.C. Пушкина о том, что язык неистощим в соединении слов. Однако же, как бы многообразны ни были возможности соединения слов, всё-таки их лексико-синтаксическая сочетаемость остаётся жёстко контролируемой, а её пределы ограничены.

По всей вероятности, количество слов, абсолютно свободных по сочетаемости, достаточно невелико. Наиболее свободными оказываются слова с прямым номинативным значением. Но даже их автономность представляется весьма иллюзорной, будучи определяемой характером предметно-логических связей мира вещей, их свойств и отношений [3].

Сущность этого феномена находит разъяснение у В.В. Виноградова: «В основном круг употребления номинативного значения слов, круг его связей соответствует связям и отношениям самих предметов, процессов и явлений действительного мира, например: пить воду, квас, вино, чай, сидр, виноградный сок и т.п.; каменный дом, подвал, фундамент, пол, сарай и т.п.; щурить, прищурить глаза» [1. С. 12].

Появление у слова новых номинативных значений, производных от уже существующего узуального значения и обусловленных необходимостью наименования новых явлений действительности, нередко завершается возникновением новых словосочетаний, необычных как по форме, так и по содержанию. При условии, если номинативно-производное значение составных элементов такого сочетания вскрывается вне корпуса всей этой единицы, она воспринимается как свободная, но имеющая потенциальные перспективы стать аналитическим построением.

Основным условием превращения свободного словосочетания в аналитическую единицу является семантический характер ключевого слова. Оно должно наполняться таким информативным содержанием, для восприятия которого требуется сформировавшаяся языковая компетенция: donner carte blanche / дать свободу действий; efforts blancs / напрасные усилия; белый билет; белое движение; сау цæсгом сыхалын / проявить дерзость; урс æнустæ / светлое будущее и т. д.

Самым заметным ограничениям в сочетаемости подвержены слова, у которых связи формируются, вследствие их семантических особенностей. Существенное отличие этих значений от номинативных состоит в том, что они отражают явления окружающей действительности не прямо, а опосредованно. Появление этих значений обусловлено тем, что из уже имеющихся в лексических ресурсах языка извлекаются новые возможности обозначить какой-либо отрезок действительности как-то иначе.

Во многих именных аналитизмах вычленение опорного слова становится контаминирующей процедурой. Например, в выражении mélancolie noire обе его составные части выступают как семантически несвободные единицы, поскольку существительное mélancolie в силу своего лексического содержания: état morbide de tristesse et de dépression. Sombre tristesse. [8. C. 606] предполагает сочетаемость лишь с прилагательными, сигнализирующими мрачные тона. В изучаемой триаде цветообозначений таким оказывается слово noir. Это последнее, обладая более широким спектром сочетаемостных возможностей, становится всё-таки несвободным в каждой конкретной узуальной модели приведённого образца. Следовательно, такие построения как mélancolie noire, four noir и т.д. являют собой бесспорный фактор контаминации двух элементов, выступающих смысловым фокусом подобных сочетаний. Точнее говоря, обе составные единицы подобных аналитизмов выступают в роли их опорного слова. Данный феномен проявляется и в русском и в осетинском языках.

Замечено, что не только приобретение новых значений (переносных или производных) ограничивает сочетаемость данного слова со своим окружением, создавая при этом связность смысла, но и утрата им информативного содержания приводит к изменению характера сочетаемости. Так, многочисленные глаголы широкого семантического объёма при обогащении своих сочетаемостных возможностей утрачивают своё первичное значение и начинают приобретать 
функции, аналогичные функциям вспомогательного глагола: faire chou blanc / a) промахнуться; b) потерпеть полную неудачу, остаться ни с чем; avoir un blanc / внезапно забыть что-л.; se faire blanc de son épée / a) доказать на поединке свою правоту; b) хвастать своим воображаемым могуществом; les mains noires font manger le pain blanc / чёрные руки добывают белый хлеб и т.д. Степень утраты первичного значения у глагола бывает различна. В зависимости от этого факта словосочетание может занимать промежуточное положение между только что упомянутым типом, где глагольная лексема подвергается десемантизации, и другим видом аналитических построений, в которых их составляющие актуализируют несвободные значения, порождаемые стереотипами мышления определённой эпохи: впасть в чёрную меланхолию (в зелёную тоску); tomber (se trouver) en mélancolie noire (en colère blanche, noire, bleue).

В русском языке явление аналитизма (именного и глагольного) наблюдается гораздо реже. Правда, сделанный вывод требует некоторых уточнений. С достаточной достоверностью можно утверждать, что русская система формирует относительно большое количество именных сочетаний, среди которых обнаруживаются даже аналоги (структурные, смысловые и образноконнотативные) уже перечисленных аналитических структур французского языка: mélancolie noire / чёрная меланхолия; misère noire / чёрная нужда; magie blanche / белая магия и т.д.

Итак, приведённые примеры позволяют констатировать, что именные аналитизмы русского языка, если и не достигают той частотности, которая присуща французскому языку, то, по крайней мере, могут считаться его достаточно обычным явлением.

Что касается аналитических структур, построенных на глаголах широкой семантики, утрачивающих в определённой мере своё лексическое содержание и приближающихся по своему статусу к вспомогательным элементам, то их число оказывается ещё более ограниченным. Приведём некоторые примеры подобных построений русского языка: довести до белого каления (его французский аналог chauffer à blanc, осетинский - туг урс кæнын); выбросить белый флаг ( hisser (arborer) le drapeau blanc).

По поводу приведённых примеров считаем необходимым сделать одно существенное замечание. Бесспорно, степень десемантизации в них глагольных элементов является гораздо более низкой, чем десемантизация глагольных словоформ французского языка. Этот факт обусловлен тем, что в русском языке нет ни одного глагола столь широкой семантики и, следовательно, максимально интенсивной десемантизации, как это наблюдается во французском языке.

Обращение к осетинскому материалу убеждает нас в том, что в его системе обнаруживается относительно большое количество аналитических образований как именной (сау хабар / плохое известие; сау кусæг / чернорабочий; сау фæндтæ / подлые намерения; сау дуг / тяжёлое время; сау тых / тёмная сила, так и глагольной модели (сау гæдытæ æппарын / говорить заведомую ложь; сау митæ кæнын / вести себя недостойно; сау тугтæ мысын / выдумывать, наговаривать; сырх зынг кæнын / раскалить(ся) докрасна, причём, именные аналитизмы осетинского языка значительно уступают место глагольным сочетаниям, поскольку 1) осетинская система отдаёт явное предпочтение свободным именным словосочетаниям и 2) осетинская система располагает достаточно разнообразными ресурсами для их формирования, назовём, прежде всего, глаголы широкой семантики: кæнын(делать), уæвын(быть) и некоторые другие.

Вопрос об опорном слове для глагольных аналитических единиц достаточно сложен: их смысловым фокусом является, бесспорно, имя существительное при реализации глагольной лексемой своего неосновного или непервичного значения. Следовательно, аналитизация таких словосочетаний становится результатом взаимодействия двух сил: синтаксической и смысловой. Те глаголы, которые обретают облик и функциональное подобие вспомогательного грамматического глагола, должны быть даны в любом лексикографическом издании в совокупности со всей суммой существительных как непосредственных реализаций их возможных сочетаемостей. В свою очередь, каждое существительное, несущее основную смысловую нагрузку, должно сопровождаться толкованиями всех его значений. Это тем более необходимо, что от того конкретного значения, которое существительное реализует в каждом из конкретных сочетаний, эти последние, строясь даже с одним и тем же глаголом, могут получать разные смысловые оттенки: a) dire blanc et noir; б) dire tantôt blanc, tantôt noir. Значения приведённых примеров следующие: 1. колебаться; не знать, какое решение принять; склоняться то к одному, то к другому решению; 2. говорить то одно, то другое. O различии смысловых оттенков в данных сочетаниях свидетельствует и русское выражение «семь пятниц на неделе», являющееся смысловым аналогом dire tantôt blanc, tantôt noir, в то время как первое (dire blanc et noir) не имеет своего русского аналога.

Характерно, что некоторые сочетания, строящиеся даже на разных глаголах, оказываются гораздо более монолитны в смысловом наполнении, чем те, которые используют один и тот же глагол: aller (changer, passer) du blanc au noir. В приведённых сочетаниях наблюдается совершенно различные процессы в выборе их смысловых фокусов. В аналитической структуре, построенной на глаголе passer,отмеченном более явной десемантизацией, чем две другие глагольные единицы (aller, changer), опорным словом выступает её именной элемент. Напротив, в двух других сочетаниях, глагольные элементы которых 
не поддаются столь интенсивной десемантизации, формируется контаминизирующий процесс в выборе их смысловых фокусов. Эти аналитические сочетания не располагают смысловыми оттенками или же вариантами смысла и переводятся на русский и осетинский языки однозначно: бросаться из одной крайности в другую, иу æгæрдзинадæй иннæмæ хауын.

Особое внимание следует обратить на те аналитические структуры, которые создаются в многообразных условиях общественно-языковой активности и представляют собой закрепление в виде мыслительного и языкового клише какоголибо свободного сочетания, реализующего номинативную функцию слова в его прямых и свободных значениях. Свободное словосочетание закрепляется практикой языка как обязательностереотипное при обозначении каких-либо элементов окружающего нас мира. В таких образованиях их составные элементы, в сущности, не подвергаются смысловым сдвигам, да и структурных изменений практически не происходит. Заметим при этом, что набор таких образований нестабилен; они меняются от эпохи к эпохе, будучи вызваны к жизни потребностями сегодняшнего дня; например, в XIX веке говорили instruction publique, а в наше время - это éducation publique.

Многие из таких словосочетаний становятся терминологическими обозначениями: vin blanc / белое вино / урс сæн; houille blanche / белый уголь / урс æвзалы; чёрное золото / сау сыгъзæрин.

\begin{tabular}{lcr}
\multicolumn{1}{c}{ Немалое } & количество & свободных \\
словосочетаний & становятся & не \\
устойчивыми, просто
\end{tabular} устойчивыми, но стереотипными клише,
типичными для речевого обихода в какой-либо определённой социальной ситуации.

Поиск опорного слова в клишированных словосочетаниях становится трудоёмкой и в деталях неоднозначной процедурой, опирающейся, однако, на единый принцип: на роль смыслового слова может претендовать та составляющая всего сочетания, которая отвергает клиширование.

Системный статус аналитических единиц, о которых идёт сейчас речь, определяется явлением социального принуждения (la contrainte sociale), но они удобны в обращении, мобильны: легко образуются, так как по синтаксической структуре они принадлежат к продуктивным типам словосочетаний. Равным образом, они легко разрушаются, когда коллективное языковое сознание больше не нуждается в них.

Таким образом, возникновение таких клишеобразных аналитических единиц и в особенности их разрушение детерминировано прежде всего социальными причинами: если модифицируется или же исчезает сама социальная ситуация, и нет более никакой необходимости както обозначать её, тогда прекращает своё существование и аналитическая структура. Образовавшееся в языке зияние вскоре заполняется каким-либо новым образованием. Язык не может существовать без штампов и клише.
Вопрос об опорном слове в аналитических словосочетаниях в определённой мере обусловлен их грамматическим типом. Исходя из того факта, что аналитические сочетания являют собой, как правило, продуктивный тип синтаксической структуры, то семантически опорное слово может, как совпадать, так и не совпадать с грамматически стержневым словом. Например, во французском языке многих стран чёрной Африки в сочетаниях oreilles rouges / белый человек, langue blanche / европейский язык, école blanche / европейская школа, опорными словами выступают прилагательные. Та же ситуация наблюдается и в русском языке: выражения белые рабы, белые негры семантически опираются на адъективные составляющие. Это же прилагательное становится опорным элементом и в других аналитических структурах: бремя белого человека (всем известно, что это выражение введено апологетом колониализма Р. Киплингом, подчёркивавшим, что белый человек, то есть европеец - это проводник цивилизации для отсталых народов), белокурая бестия, белая Арапия и т.д.

Особое внимание хотелось бы обратить на образование сочетания blanc bec. Фразеологический словарь под редакцией Я.И. Рецкера регистрирует его в значении «молокосос» [6. С. 129]. Обратим при этом внимание на некоторые различия в лексикографическом облике данного сочетания. В частности, в Новом французско-русском словаре [С. 121] его составные элементы пишутся через дефис и сопровождаются пометой «разг.». Во фразеологическом словаре под редакцией Рецкера оба эти признака (дефис и стилевая помета) отсутствуют. Уже эта морфологическая характеристика подталкивает нас к выводу о том, что мы имеем дело со словосочетанием. Вместе с тем, препозиция прилагательного blanc, долженствующего, как и другие односложные прилагательные, обозначающие цвет, уйти в постпозицию, свидетельствуют, скорее, о том, что данное образование является типичным для французского языка композитом. Сложные слова нас не интересуют, так как предметом наших размышлений выступают аналитические единицы.

Сказанное относится и к другому образованию - blanc estoc, фигурирующего в двух упомянутых словарях [6. С. 417; 4. С. 121]. Причём, характер транскрипции, предлагаемой двуязычным словарём [blãkestok] склоняет нас к восприятию данной единицы как словосочетания, а взаимное расположение в ней её составных элементов (то есть синтагматический фактор) убеждает нас в том, что в ней доминируют признаки композита. Двойственная природа таких образований бесспорна, их лексикографический статус не совсем ясен.

Компромиссное решение, которое в слагающейся ситуации представляется наиболее рациональным, может обрести вид рабочего допущения того, что образования типа blanc-bec, blanc-estoc - это своеобразные синтаксические 
конструкции, аналитический характер которых поддерживается определённой устойчивостью их смыслового содержания и заметным ослаблением их внутренних синтаксических отношений. Заметим, что первый из приведённых примеров blanc-bec расширил своё смысловое содержание и стал адекватен аналитической структуре homme blanc, то есть белый человек, представитель белой расы (race blanche).

Вполне очевидно, что опорными элементами во всех этих словосочетаниях выступают слова цветовой номинации. Список таких построений можно дополнить и другими сочетаниями: pères blancs (так называется в Африке одна из миссионерских организаций), drapeau blanc (как символ поражения или заявления об отсутствии агрессии), белая тишина (сочетание, употреблённое К. Паустовским, импрессионистские эксперименты которого в литературе бесценны) и т.д.

Уместно было бы остановиться на роли белого цвета (красного - тоже, хотя и в меньшей степени) при формировании аналитических структур политической и идеологической смысловой отнесённости.

В XX веке прилагательные «белый» и «красный» сформировали устойчивую антонимическую пару, хотя ещё с конца XVIII века во Франции кратковременная власть династии Бурбонов противопоставила красному революционному флагу белый цвет, ставший символом монархического управления государством.

Drapeau blanc - это незыблемый знак монархической системы. Символика белого (то есть монархического) цвета была заимствована приверженцами монархического строя уже в нашем Отечестве, когда, после победы большевиков в 1917 году, высшие чины русской армии присягнули царю на верность [2. С. 80]. Так появилось в российской истории политическое понятие «белая гвардия» (вечным памятником этому семантическому неологизму в русском языке можно считать, бесспорно, известный роман Булгакова, который так и называется «Белая гвардия»), а в русском языке - аналитическая конструкция, где опорным словом выступает прилагательное «белый». Прочная антонимическая пара («белый / красный») ещё более отточила свой смысл во время гражданской войны 1918 года, когда сторонники монархии и противники большевиков объединились в так называемую белую армию, а рабочие и крестьяне под руководством большевиков создали красную армию. Вполне естественно, что в своём подавляющем большинстве эти сочетания, отражающие исторические реалии российской истории органично вошли и в ткань осетинского языка: сырх тырыса / красное знамя, Сырх Æфсад / Красная Армия, сырх партизан / красный партизан, урс пъагонджынтæ / белые погоны.

Слово белый относится к числу ключевых в публицистике русской эмиграции двух первых волн. В русской эмигрантской публицистике появилось целое множество аналитических сочетаний, построенных на опорном слове белый: белое прошлое, белая борьба, белое движение, белые ряды, белая политика, белая идея, белая власть, белый (а также красный) террор. Вынужденная эмиграция из России огромной массы её граждан в 20-е годы минувшего века обусловила появление таких формулировок, как белый изгнанник, белая эмиграция. Беженцы из России именовались во Франции белыми русскими (Russes-Blancs). Этот интенсивный языковой процесс, вызванный к жизни социальнополитическими коллизиями, ярко отражён в творчестве многих литераторов.

Всё сказанное позволяет утверждать, что вопрос об опорном слове аналитической единицы представляется достаточно сложным. Он становится ещё сложнее там, где речь идёт о тех словосочетаниях, которые существуют в парах. Причём, одно из них являет собой свободное сочетание слов (например, чёрный пояс в таком предложении: «Девушке подарили чёрный пояс к её серебристо-тёмному платью»), другое аналитическую единицу, подвергшуюся экспрессивной обработке и получившую переносно-образное значение: Чёрный пояс позволяет ему участвовать в самых престижных соревнованиях мирового уровня. Сопоставляя одно и то же сочетание слов (чёрный пояс), употреблённых в разных языковых ситуациях, убеждаемся, что образное содержание создаётся в нём не изменением в значениях входящих в него слов, а изменением значения всего словосочетания. Переносно-образный смысл, доминирующий над заметно разрушающимися синтаксическими отношениями, и становится основной причиной превращения свободного словосочетания в аналитическую структуру. Параллельное существование в каком-либо языке свободных и аналитических сочетаний слов, построенных на идентичных лексических составляющих, можно оценить как особый случай смысловой и синтаксической омонимии. Например: a) Une belle robe blanche cousue avec de fils blancs allait à la perfection à la jeune mariée; б) Cette histoire cousue de fils blancs commence à m'agacer.

Как по структуре, так и по характеру переносно-образных преобразований параллельные словосочетания многообразны. Это могут быть полновесные синтагмы, позволяющие эксплицировать в них субъектно-предикативные отношения (avoir les mains noires / быть виновным, иметь судимость; rendre noir / чернить, оклеветать; être noir de coups / быть избитым до синяков; être dans le noir / быть в полной неизвестности; peindre tout en noir / изображать всё в чёрных красках; voir tout en noir / видеть всё в мрачном свете). Но, очевидно, самой предпочтительной структурной моделью в узусе языка оказываются именные сочетания данного вида: pain noir / чёрный хлеб (вспомним название известного романа Ж.-П.Шаброля «Les enfants du pain noir», переводимого на русский язык как «Дети чёрной нищеты»); 
machins noirs / мрачные измышления; travail noir / работа левая, незаконная; bête noire / пугало, предмет особой ненависти и т.д.

Как уже было упомянуто, переносно-образные преобразования словосочетаний также многообразны, но самыми действенными являются, очевидно, процессы гиперболизации: mettre qn à blanc / арго a) обыграть кого-либо дочиста, b) разорить до тла, оставить в одной рубашке; saigner à blanc / обескровить, истощить; разорить, пустить по миру; cracher blanc / мучиться, изнывать от жажды; être réduit à blanc estoc / разориться до тла; se manger (se bouffer) de blanc des yeux / ссориться, грызться; être fauché à blanc / быть совсем разорившимся, совсем нищим и т.д. В подобных словосочетаниях слагаются значения как результат ассоциаций по смежности.

Вопрос опорного слова решается не просто для тех аналитических единиц, в которых основной причиной смысловой целостности выступает характер синтаксического отношения их структурных компонентов, обусловленный их лексическими признаками. Так, например, во французских выражениях peur noire / панический страх; colère bleue (jaune, blanche, rouge, noire) / ярость; en faire voir de bleues (de grises, de vertes, de toutes les couleurs) / разг. отделать, проучить; название конкретного цвета не столь важно, как указание на интенсивность процесса или действия. По всей вероятности, именно лексический фактор, будучи определяющим в функционировании синтаксической структуры, должен учитываться как ведущий при вычленении в составе аналитической структуры описанного вида её опорного элемента.

В том случае, если аналитическая единица не имеет в своём составе лексической составляющей с ярко выраженной смысловой нагрузкой, роль опорного слова берёт на себя тот компонент, который выступает в ней грамматическим стержнем: ne connaître ni le blanc ni le noir / не отличать чёрное от белого, ничего не знать, не смыслить. В приведённом примере, построенном на переходном глаголе, отмеченном, как и любая транзитивная лексема, семантической недостаточностью, грамматическим центром синтаксической единицы и, следовательно, опорным словом выступает целостная синтагма, слагающаяся из сказуемого и прямого дополнения.

Достаточно однозначной и элементарно простой процедурой становится выделение опорного слова для тех аналитических структур, которые представлены целой серией однотипных построений, группирующихся вокруг одного слова. Оно-то и должно быть признано опорным компонентом, при условии, разумеется, если вне целой серии аналитических построений, даже и структурно самых разнообразных, это слово не употребляется в данном значении: passer du blanc au noir / бросаться из одной крайности в другую; aller du blanc au noir / бросаться из одной крайности в другую; changer du blanc au nour / бросаться из одной крайности в другую; saigner au blanc / обескровить; разорить; saigner jusqu'au blanc / разорить кого-либо дотла; réduire qn au blanc / разорить кого-либо дотла. Во всех перечисленных словосочетаниях опорным компонентом выступает слово blanc.

Таковы реальные и вероятностные коллизии лексического, семантического и структурного порядка, свершающиеся при выделении в аналитической единице дофразеологического уровня её опорного компонента. Памятуя, что два первых подвида в общей совокупности аналитических единиц фразеологического уровня (единства и сочетания) тяготеют, скорее, к аналитическим структурам первой ступени устойчивости, мы должны без колебаний отнести всё сказанное и к этим последним. Что касается третьего вида аналитических структур собственно фразеологической природы, то, исходя из ряда факторов (высшей степени переосмыслений настигающих практически все их составные части, наличие какого-либо слова как смыслового фокуса всей единицы и отправной точки в формировании её образности, ослаблении, вплоть до полного разрушения внутренних синтаксических отношений), нам следует признать опорным компонентом ту составляющую всего сочетания, на которой лежит ответственность за формирование его смыслового фокуса и его образности: avoir les mains blanches / быть невиновным, не иметь судимости; avoir les mains noires / быть виновным; manger son pain blanc le premier / быть нерасчётливым; être dans de beaux draps blancs / оказаться, находиться в пренеприятном, в затруднительном положении и т.д.

На основании изложенных данных допустимо сделать вывод о том, что выделение опорного слова в аналитической единице опирается на совокупность её лексических, семантических и структурных характеристик при обязательном учёте таких её признаков, как индивидуальный смысл и формируемый образ.

Наиболее стереотипным элементом в выборе опорного слова аналитическим сочетанием глагольного типа будет то существительное, которое вступает в соединение с глагольной лексемой в её вторичной номинативной функции. Аналитизация таких словосочетаний становится, таким образом, результатом двух сил одновременно: синтаксической и смысловой.

В именных аналитизмах вычленение опорного слова становится, как правило, контаминирующей процедурой, предполагающей, что в составе словосочетания обе его структурные составляющие семантически несвободны в силу ограничения их сочетаемостных возможностей рядом факторов (анимизмом, лексической антиномией и т.д.), выступая, таким образом, его смысловым фокусом.

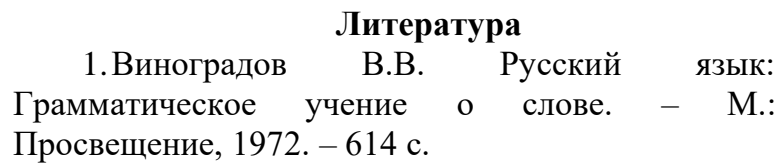

\section{Литература}

Просвещение, 1972. - 614 с. 
2.Зеленин А.В. Из истории политического лексикона XX века. «Красныцй» в русской эмигрантской публицистике // Русская речь. - 1995. №5. - C. 91-96.

3. Уёмов А.А. Вещи, свойства и отношения. М.: Изд-во Акад. наук СССР, 1963. - 184 с.

4.Гак В.Г., Ганшина К.А. Новый французскорусский словарь = Nouveau Dictionnaire FransçaisRusse. - М.: Русский язык, 1995. - 1195 с.

5.Осетинско-русский словарь = Иронуырыссаг дзырдуат / Под ред. А.М. Касаева. Владикавказ: СОИГИ, 1993. - 384 с.

6. Французско-русский фразеологический словарь / Под ред. Я.И. Рецкера. - М.: Гос. изд-во иностр. и нац. словарей, 1963. - 1112 с.
7.Щерба Л.В., Матусевич М.И. Большой русско-французский словарь. - М.: Русский язык, 2000. -852 c.

8. Dictionaire du français contemporain. Larousse. - Paris (6), 1980. - 1263 p.

9.Нарты кадджытæ. - Дзæуджыхъæу: Гасситы Викторы номыл рауагъдадон - полиграфион куыстуат, 1995. - 408 ф.

10. Тедеты Е. Хæхты дзæнгæрæг.

Орджоникидзе: Ир, 1989. - 151 ф.

11. Хостыхъоты 3. Уарзондзинады монолог. Орджоникидзе: Ир, 1975. - 98 ф. 